\title{
HEAT AND MASS TRANSFER DURING HEATING OF COAL-WATER FUEL PARTCALES COATED WITH A WATER FILM IN A HIGHT TEMPERATURE GAS MEDIUM
}

\author{
Vladimir V. Salomatov*, Samen V. Syrodoy**a, Nadegda Y. Gutareva** \\ * Institute of Thermophysics. S.S. Kutateladze, 630090 Novosibirsk, Russia \\ ** National Research Tomsk Polytechnic University, 634050 Tomsk, Russia
}

\begin{abstract}
The problem has been solved numerically of ignition particles of coal-water fuel (CWF), covered with a water film. The effect of water evaporation in the process of preparation and thermal ignition of the fuel has been achieved. It has been shown that heating of the primary fuel takes place even in the near-surface water film conversion. The scale of the effect of heat transfer conditions on the temporal characteristics of the water film evaporation and ignition of coalwater fuel particles has been achieved.
\end{abstract}

\section{INTRODUCTION}

Coal-water fuel (CWF) is one of the most promising areas of power system for the next decade [1]. But the introduction of technology CWF has been constrained by a number of objective reasons. One of them is the absence of a general theory of combustion, and in particular the ignition of the fuel particles in a high temperature gas environment. Designed to date models and methods for solving relevant problems [2 - 4] does not fully take into account a complex set of co-occurring in the induction period of physical and chemical processes near the surface and in the particle coal-water fuel. Thus, for example, in [2 - 4] the variants of the process are not considered in the case of forming particles CWF completely coated with a thin layer of water film. This configuration is the most likely as a result of cooking and spray water coal suspensions [5]. This is confirmed by a number of experimental [6] and numerical studies [7].

It is of interest to determine the conditions and characteristics of the ignition CWF particles coated with a film of water. It should be noted that the experimental study of the basic laws of these processes in the near future is unlikely in view of the fact that typical particle sizes CWF inlet into the combustion space (taking into account the current level of technology of the nozzle [8]) are 0,08 to $1 \cdot 10^{-3} \mathrm{~m}$ and the characteristic times of the process should not be (in terms of efficient combustion conditions CWF) exceed 1.5-2 seconds [9] in the most adverse conditions, the thermal effect on the particle. Modern technologies such as PIV, LSV, PTV [10] and etc. effective in experimental studies patterns of movement (track log) of finely dispersed particles [11] (including water drops with foreign inclusions). But in the motion of particles CWF these methods do not provide an acceptable level of error analysis of measurement results due to the heterogeneity of the fuel particles and the difficulty of administration "tracers" in the object of study.

It may be noted that conditions for the ignition of coal-water fuel may influence the particle shape, which in this case is mainly dependent on the configuration of the main cell fuels (coal), surrounded by a film of water. However, we can see in the experiments [12,13] that the water droplets (including with solids) in flight continuously deform under the forces of inertia, viscosity, surface tension and gravity cycles.

During one such cycle, the droplet shape changes of 5-6 times. Therefore, the problem of ignition CWF particles coated with a film of water can be solved with the use of a two-layer model of an inhomogeneous field. The probability of such a configuration, the motion of the particle in a water shell CWF is not less (and perhaps, given the continuous, according to [14] transients), even higher than any other registered configuration [15] drops of water moving in the field of mass forces in a highimpact exterior medium.

Purpose - the solution of coal-water fuel ignition particles in the form of a sphere covered with a thin film of water under intense warming in the high temperature gas environment.

\section{STATEMENT OF THE TASK}

Adopted by the statement of the problem, which differs from the previously developed [2 — 4] that examines the ignition coated with a film of water particles CWF. During the simulation that is focused on the description of complex physical and chemical processes that occur in the induction period. Evaporating water film from the surface of the particles and then (after the

${ }^{\mathrm{a}}$ Corresponding author: syrodoy@tpu.ru

This is an Open Access article distributed under the terms of the Creative Commons Attribution License 4.0, which permits unrestricted use, distribution, and reproduction in any medium, provided the original work is properly cited. 
evaporation of the surface layer water) post-dripping layer of basic fuel are the most important (energy consumption). As a result, a dehydrated porous body is formed (with a high thermal resistance) through which the filtered pairs (formed by the evaporation of water), cooling it, and joining the thermochemical interaction with carbon. It should be noted that the processes of evaporation, are among the most complex in the mathematical description. Typically, for such tasks various simplifying assumptions can be used (equilibrium parameters on the boundary of a phase transition [2], "smearing" of the evaporation front of the space [9]), which can lead to significant errors in calculation. However, it is known [10] that the evaporation of water can be held in almost any temperature (in the range of $\mathrm{T}_{\mathrm{f}}<\mathrm{T}<\mathrm{T}_{\mathrm{b}}, \mathrm{T}_{\mathrm{f}}$ - the freezing point, boiling point - boiling point). Therefore, the formulation of the problem has been used for well-established scheme [3,4] that describes the process of "dewatering" of porous carbon particles in a high-temperature gas environment.

By analogy with $[3,4]$ and taking into account the above simplified mathematical formulation of the problem of heat and mass when ignited coal-water fuel particles are formulated in the following non-stationary system of differential equations:

The energy equation for the source of the fuel:

$$
C_{1} \rho_{1} \frac{\partial T_{1}(r, t)}{\partial t}=\frac{1}{r^{2}} \frac{\partial}{\partial r}\left[r^{2} \cdot \lambda_{1} \cdot \frac{\partial T_{1}(r, t)}{\partial r}\right]
$$

The energy equation for the "dry" part of the CWF:

$$
C_{2} \rho_{2} \frac{\partial T_{2}(r, t)}{\partial t}=\frac{1}{r^{2}} \frac{\partial}{\partial r}\left[r^{2} \cdot \lambda_{2} \cdot \frac{\partial T_{2}(r, t)}{\partial r}\right]-\sum Q_{i} \cdot W_{i}-u C_{P} \cdot \rho_{s} \frac{\partial T_{2}(r, T)}{\partial r},
$$

The energy equation for the water film:

$$
C_{3} \rho_{3} \frac{\partial T_{3}(r, t)}{\partial t}=\frac{1}{r^{2}} \frac{\partial}{\partial r}\left[r^{2} \cdot \lambda_{3} \cdot \frac{\partial T_{3}(r, t)}{\partial r}\right] .
$$

Where: $\mathrm{T}_{\mathrm{e}}$ - evaporation temperature at the boundary, $\mathrm{K} ; \mathrm{T}_{\mathrm{ws}}$ - temperature at the surface of the water film, $\mathrm{K} ; \mathrm{Q}_{\mathrm{i}}-$ standard enthalpy of formation, $\mathrm{J} / \mathrm{kg} ; \mathrm{W}_{\mathrm{i}}$ - the speed of a chemical reaction $\mathrm{kg} /\left(\mathrm{m}^{2} \cdot \mathrm{s}\right)$; $\mathrm{u}$ - the rate of filtration of water vapor $\mathrm{m} / \mathrm{s} ; \lambda_{1}$ - coefficient of thermal conductivity of the initial part of the CWF W/(m.K); $\lambda_{2}$ - the thermal conductivity of the dry part of CWF, W/(m.K); $\lambda_{3}$ — coefficient of thermal conductivity of water, $\mathrm{W} /(\mathrm{m} \cdot \mathrm{K}) ; \mathrm{C}_{1}$ — the source of the heat capacity of the $\mathrm{CWF}, \mathrm{J} /(\mathrm{kg} \cdot \mathrm{K}) ; \mathrm{C}_{2}$ - specific heat of the dry part of $\mathrm{CWF}, \mathrm{J} /(\mathrm{kg} \cdot \mathrm{K}) ; \mathrm{C}_{3}$ - heat capacity of water, $\mathrm{J} /(\mathrm{kg} \cdot \mathrm{K}) ; \rho_{1}-\mathrm{the}$ density of the initial part of the CWF, $\mathrm{kg} / \mathrm{m}^{3} ; \rho_{2}$ - dry density of the $\mathrm{CWF} \mathrm{kg} / \mathrm{m}^{3}, \rho_{3}$ - water density $\mathrm{kg} / \mathrm{m}^{3}, \mathrm{C}_{\mathrm{P}}$ - isobaric heat capacity of water vapor $\mathrm{J} /(\mathrm{kg} \cdot \mathrm{K}) ; \rho$ - density of the steam $\mathrm{kg} / \mathrm{m}^{3} ; \mathrm{r}_{\mathrm{e}}$ - evaporation front radius, $\mathrm{m} ; \mathrm{r}_{0}$-outer radius of the particle $\mathrm{CWF}$, $\mathrm{m} ; \mathrm{r}_{\mathrm{ws}}$ -outer radius of the particles with a water film, $\mathrm{m}$.

At the interface of the "original CWF — water film" 4 the boundary condition of the second kind, is provided the ideal contact:

$$
\left.\lambda_{2} \frac{\partial T_{2}\left(r_{0}, t\right)}{\partial r}\right|_{r=r_{0}-0}=\left.\lambda_{3} \frac{\partial T_{3}\left(r_{0}, t\right)}{\partial r}\right|_{r=r_{0}+0}, \quad T_{2}\left(r_{0} ; t\right)=T_{3}\left(r_{0} ; t\right)
$$

At the interface of the "original CWF - dry coal" evaporates. Accordingly, there is the boundary condition of the 4th kind, taking into account the heat of the phase transition:

$$
\left.\lambda_{1} \frac{\partial T_{1}(r, t)}{\partial r}\right|_{r=r_{e}-0}-\left.\lambda_{2} \frac{\partial T_{2}(r, t)}{\partial r}\right|_{r=r_{e}+0}=Q_{e} \cdot W_{e}, \quad T_{1}\left(r_{e} ; t\right)=T_{2}\left(r_{e} ; t\right)=T_{e}
$$

Mass rate of evaporation $\left(\mathrm{W}_{\mathrm{e}}\left[\mathrm{kg} /\left(\mathrm{m}^{2} \cdot \mathrm{s}\right)\right]\right)$ has been calculated from the expression:

$$
W_{e}=W_{0} \cdot \exp \left(\frac{Q_{e} \cdot \mu \cdot\left(T_{e}-T_{f}\right)}{R \cdot T_{f} \cdot T_{e}}\right) .
$$

Where: $\mathrm{T}_{f}$ - water temperature corresponding to the freezing point, $\mathrm{K} ; \mu$-molar mass of water vapor $\mathrm{kg} / \mathrm{mole}$; $\mathrm{R}-\mathrm{universal}$ gas constant, $\mathrm{J} /($ mole $\cdot \mathrm{K}) ; \mathrm{W}_{0}$ — mass flow rate of water evaporation at $\mathrm{T}_{\mathrm{f}}, \mathrm{kg} /\left(\mathrm{m}^{2} \cdot \mathrm{s}\right)$; $\mathrm{Q}_{\mathrm{e}}$ is the thermal effect of the evaporation of water, $\mathrm{J} / \mathrm{kg}$.

Coordinate border has been evaporated from the expression:

$$
r_{F}=r_{0}-\int_{0}^{\tau} u_{F} d \tau
$$

$\mathrm{u}_{F}=\mathrm{W}_{\mathrm{s}} / \mathrm{p}_{\mathrm{W}}$ - linear speed of advance of the evaporation front, $\mathrm{m} / \mathrm{s}$.

The pressure distribution of evaporated water by filtration through a porous carbon skeleton of the radius of the particle is described by the equation of filtration:

$$
\frac{m \cdot v \cdot Z}{K_{P}} \frac{\partial p_{s}(r, t)}{\partial t}=\frac{1}{r^{2}} \frac{\partial}{\partial r}\left(\frac{1}{r^{2}} \frac{\partial p_{s}(r, t)}{\partial r}\right)
$$

The filtration rate has been calculated using a pair of mathematical expressions Darcy's law:

$$
u=-\frac{K_{P}}{v} \frac{\partial p_{s}}{\partial r}
$$

Where: $\mathrm{p}_{\mathrm{s}}$ - vapor pressure, $\mathrm{Pa} ; \mathrm{m}$-porosity; $\mathrm{Z}$ - compressibility of water vapor $1 / \mathrm{Pa} ; \mathrm{K}_{\mathrm{P}}$-permeability porous structure, $\mathrm{m}^{2} ; \mathrm{v}-$ dynamic viscosity of water vapor $\mathrm{Pa} \cdot \mathrm{s}$. 
Water vapor enters the endothermic chemical reaction with carbon (remaining after the completion of dripping). The rate of reaction $\mathrm{C}+\mathrm{H}_{2} \mathrm{O}=\mathrm{CO}+\mathrm{H}_{2}-118.485 \mathrm{MJ}$ calculated from the following expression:

$$
W_{i}=k_{i} \cdot c_{i} \cdot \rho_{s} \cdot \exp \left(-\frac{E}{R \cdot T(r, t)}\right) .
$$

Where $\mathrm{k}_{\mathrm{i}}$ - preexponent reaction, $1 / \mathrm{s} ; \mathrm{c}_{\mathrm{i}}$ - the concentration of the corresponding component of the chemical reaction; $\mathrm{E}-$ activation energy $\mathrm{J} /(\mathrm{mole} \cdot \mathrm{K}) ; \mathrm{i}$ - ordinal number of chemical reactions;

Upon reaching the surface conditions of the particles $T \geq T_{\text {std }}\left(T-\right.$ the temperature of the surface of $T_{\text {std }}-$ the start of the thermal decomposition temperature) in the particle the decomposition of the organic portion of the fuel with the release of volatiles begins. The process is described by the thermal decomposition of chemical kinetics:

$$
\frac{\partial \eta_{2}(r, t)}{\partial t}=\left(1-\eta_{2}(r, t)\right) \cdot k_{i} \cdot \exp \left(-\frac{E}{R \cdot T_{1}(r, t)}\right),
$$

Pyrolysis rate has been calculated using the following expression:

$$
W_{i}=(1-\eta(r, t)) \cdot k_{i} \cdot \rho_{2} \cdot \exp \left(-\frac{E}{R \cdot T(r, t)}\right) .
$$

$\eta(\mathrm{r}, \mathrm{t})$ - parameter burnout.

The products of thermal degradation and chemical interaction of solid carbon and water vapor are blown in the "near-wall" and as a result the gas mixture is formed ignited when the critical temperature and concentration. The time period from the start of the heat exposure on the particle prior to intense (with the appearance of the flame) chemical interactions with the oxidant gas mixture is considered the ignition delay time. Near the surface of the particles the following reaction has been taken into account:

$$
\begin{aligned}
1 . \mathrm{H}_{2}+0.5 \cdot \mathrm{O}_{2}= & \mathrm{H}_{2} \mathrm{O}+141900 \mathrm{~J} / \mathrm{kg} ; \quad 2 . \mathrm{CO}+0.5 \cdot \mathrm{O}_{2}=\mathrm{CO}_{2}+10090 \mathrm{~J} / \mathrm{kg} ; \\
& \text { 3. } \mathrm{CH}_{4}+\mathrm{O}_{2}=\mathrm{CO}_{2}+\mathrm{H}_{2} \mathrm{O}+55546 / \mathrm{kg} .
\end{aligned}
$$

The rate of these reactions is calculated from the mathematical expression of the Arrhenius law:

$$
W_{i}=k_{i} \cdot c_{i} \cdot \rho_{i} \cdot \exp \left(-\frac{E}{R \cdot T(r, t)}\right) .
$$

The system of equations (1-11) has been solved with the following boundary conditions and closing ratios: $0<r<r_{0}, T(r, 0)=T_{0}, p(r, 0)=p_{0}, \eta(r, 0)=\eta_{0}$,

$-\lambda_{2} \frac{\partial T_{2}\left(r_{0}, t\right)}{\partial r}=\alpha \cdot\left[T_{c}-T_{2}\left(r_{0}, t\right)\right]+\varepsilon_{2} \cdot \sigma \cdot\left[T_{c}^{4}-T_{2}^{4}\left(r_{0}, t\right)\right]+\sum_{i} Q_{i} \cdot W_{i}$ $t>t_{\text {ews }}$,

$-\lambda_{3} \frac{\partial T_{3}\left(r_{0}, t\right)}{\partial r}=\alpha \cdot\left[T_{c}-T_{3}\left(r_{w s}, t\right)\right]+\varepsilon_{3} \cdot \sigma \cdot\left[T_{c}^{4}-T_{3}^{4}\left(r_{w s}, t\right)\right]-Q_{e} \cdot W_{e}$,

$t<t_{\text {ews }}$,

$\frac{\partial T_{1}(0, t)}{\partial r}=0$

$\frac{\partial p_{s}\left(r_{e}, t\right)}{\partial r}=-\frac{v}{K_{P}} u_{s}\left(r_{e} ; t\right)$,

$p\left(r_{0} ; t\right)=p_{0}$.

The designations: $\mathrm{T}_{0}$ - the initial temperature of the particles, $\mathrm{K} ; \mathrm{T}_{\mathrm{s}}$ - ambient temperature, $\mathrm{K}$; $\mathrm{t}_{\mathrm{ews}}$ - evaporation temperature water film, $\mathrm{K} ; \sigma-$ constant of blackbody radiation, $\mathrm{W} /\left(\mathrm{m}^{2} \cdot \mathrm{K}^{4}\right) ; \varepsilon_{2}$ - integrated emissivity water-coal particles; $\varepsilon_{3}-$ integrated emissivity film of water; $\alpha$ - the coefficient of convective heat transfer, $\mathrm{W} /\left(\mathrm{m}^{2} \cdot \mathrm{K}\right) ; \mathrm{p}_{0}$ is the initial pressure, Pa; $\eta_{0}-$ the initial value of burnout; $\left(\sum Q_{i} \cdot W_{i}\right)-$ complex, taking into account the thermal effects of the interaction of thermochemical pyrolysis products with the oxidant, $\mathrm{W} / \mathrm{m}^{2} ; Q_{\varepsilon} \cdot W_{\varepsilon}$ - complex, taking into account the thermal effects on evaporation of the water film, $\mathrm{W} / \mathrm{m}^{2}$.

The boundary value problem (1) - (17) has been solved in the time period until the conditions on the surface of the particle ignition CWF adequate conditions of ignition of solid fuels [18] during the local heating and liquid fuel condensed substances [19].

The research has been conducted under the following initial data: $\mathrm{T}(\mathrm{r}, 0)=\mathrm{T}_{0}=293 \mathrm{~K} ; \mathrm{p}_{0}=101325 \mathrm{~Pa} ; \eta_{0}=0$.

\section{Results and discussion}

The results of an experimental study of the thickness $(\delta)$ of the film of water formed in the preparation of coal-water particles have not been published practically. Therefore, we consider the most likely practical range of values $\delta\left(2 \div 6 \cdot 10^{-5} \mathrm{~m}\right)$. The time delay of ignition particulate coal-water fuel initial diameter $\mathrm{d}=0.4 \cdot 10^{-3} \mathrm{~m} \mathrm{c}$ considering the evaporation of the surface water layer has been given on the figure 1. The analysis of the dependency indicates that the evaporation process of the film slows the ignition particulate coal-water fuel. Such an increase in the ignition delay does not exceed $30 \%$ over the entire range of possible thicknesses of a film of water. The dependence 5-7 on the figure 1, it can be noted that at relatively low ambient temperatures (T $<1200 \mathrm{~K})$ the effect of evaporation of the surface of the film becomes more significant.

Depending (5-7) can show (Fig. 1), that the water film evaporation time occupies a significant portion (about 60\%) total 
induction period. It can be concluded that the conversion of the surface layer of water is one of the key steps of thermal treatment.

The temperature distribution along the radius of the particle in the moment of ignition CWF and complete evaporation of the water film with a thickness of about 20 microns last have been given on the figure 2 . We can say that there are cases of ignition

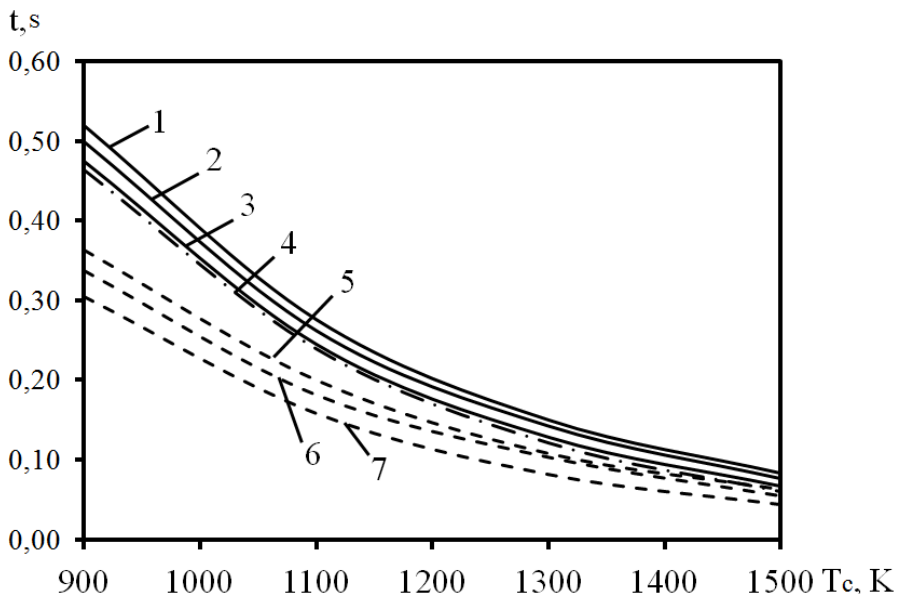

Figure.1. the dependence of the ignition delay CWF particle diameter $\mathrm{d}=0.4 \cdot 10^{-3} \mathrm{~m}$ and evaporation of the water film on the ambient temperature when the thickness of the water layer $\delta: 1,5-0.06$. $10^{-3} \mathrm{~m} ; 2,6-0.04 \cdot 10^{-3} \mathrm{~m} ; 3,7-0.02 \cdot 10^{-3} \mathrm{~m} ;(1-3)$ - particles with the surface film, 4 - particles with no water film, $(5-7)-$ the time of evaporation water film.

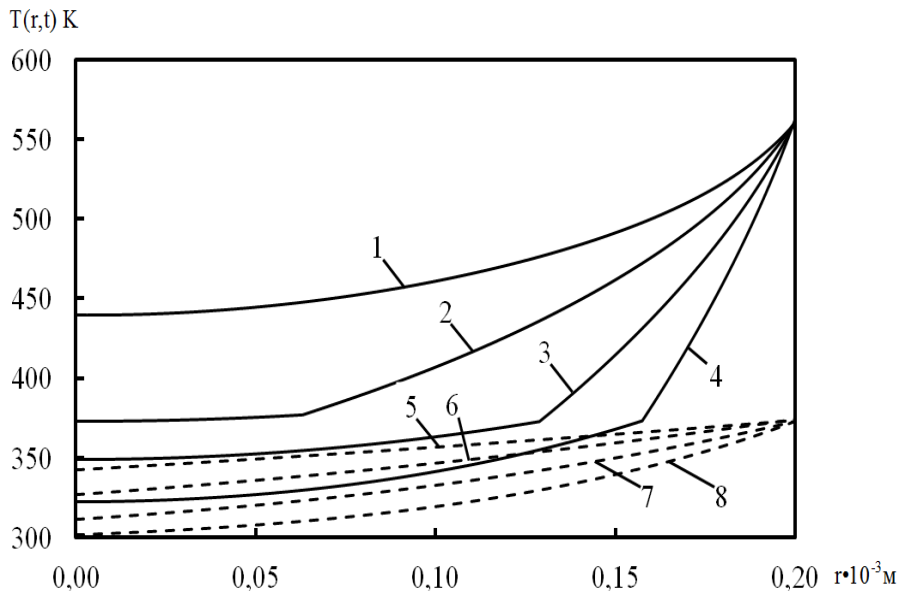

Figure.2. The temperature distribution in the particle diameter CWF $\mathrm{d}=0.4 \cdot 10^{-3} \mathrm{~m}$ at the time of ignition (1-4) and the evaporation of water $(5-8)$ at the film thickness of the latter $\delta=0.02 \cdot 10^{-3} \mathrm{~m}$ and ambient temperatures:

$1,5-\mathrm{Tc}=900 \mathrm{~K} ; 2,6-\mathrm{Tc}=1100 \mathrm{~K} ; 3,7-\mathrm{Tc}=1300 \mathrm{~K} ; 4,8-$ $\mathrm{Tc}=1500 \mathrm{~K}$

of particles of coal-water fuel in the context of the ongoing evaporation. As a result, conventionally there are two modes of ignition "low temperature" $\left(\mathrm{T}_{\mathrm{c}}<1100 \mathrm{~K}\right)$, at which ignition occurs only after-dripping, and "high temperature" $\left(\mathrm{T}_{\mathrm{c}} \geq 1100 \mathrm{~K}\right)-$ WCF ignited before the final "dewatering". Accordingly, the burning of the "watered" fuel will be significantly different from the combustion of dry coal.

Analysis of temperature fields of the particle at the time of the complete evaporation of the water film shows that, together with the evaporation of surface water is also carried out and warming up the basic layer of fuel. As a result, post-dripping occurs much faster. This fact confirms the conclusion that the process of evaporation of the water film is the main stage of thermal preparation.

\section{References}

1. $\quad$ Longwell J.P. Rubin E.S. Wilson J. Prog. Energy Comb. Sci. Vol. 25. 1995. P. 269-360.

2. Salomatov V.V. Kravchenko I.V. Burning and plasma chemistry Vol. 5. 2007. No. 3. p. 178-188.

3. Salomatov V.V. Syrodoy S.V. Gutareva N.Y. EPJ Web of Conferences 82. 01037 - 2015.

4. Salomatov V.V. Syrodoy S.V. Gutareva N.Y. EPJ Web of Conferences 76. 01018 - 2014.

5. Borzov A.I. Baranova M.P. Solid Fuel Chemistry. 2006. No 4. p.40-45.

6. Senchurova Y.A. Bulletin Tomsk Polytechnic. University - 2008. - T.312. N 4. - pp. 37-40.

7. Murko V.I. Polzunovsky Gaz. No 2/1. 2011. p.230-234.

8. Taymarov M.A. Safin R.G. Bulletin Kasan tech. University Vol. 15. 2012. No 16. p.144-145.

9. Dorokhova U.V. Syrodoy S.V. Salomatov V.V. Energy: miscellany scientific works edition.18. Novosibirsk: Novosibirsk State Technical University. 2014. p.18-32.

10. Alekseenko S.V. Bilsky A.V. Dulin V.M. Markovich D.M. Int. J. Heat and Fluid Flow. Vol. 28. 2007. pp. 1340-1359

11. Sergey V.S. Alekseenko A.V. Bilsky V.M. Dulin and Dmitriy M. M. Int. J Heat Fluid Flow. Vol.28. 2007. p.1340-1359

12. Kuznetsov G.V. Strizhak P.A. Technical Physics Letters. Vol 40. 2014. No 6. p. 499-502.

13. Volkov R.S. Kuznetsov G.V. Strizhak P.A. Technical Physics, Vol 59, 2014. No 7. p. 959-967.

14. Kuznetsov G.V. Strizhak P.A. High Temperature, Vol 52. 2014. No 4. p. 568-575.

15. Vysokomornaya O.V. Kuznetsov G.V. Strizhak P.A. IFZh Vol 86. 2013. No 1. p. 62-68.

16. Kolesnikov, A.G., Martynov, G.A. Data on laboratory research of frozen soil. Vol 1. 1953.

17. Markov I.I. Sat. Scien. tr. Vol. 6. 2002. P. 48-55.

18. Glushkov D.O. Kuznetsov G.V. Stpizhak P.A. Russian Journal of Physical Chemistry B. Vol. 5. 2011. No. 6 p.1000 - 1006.

19. Vysokomornaya O.V. Kuznetsov G.V. Strizhak P.A. Russian Journal of Physical Chemistry B. Vol. 5. 2011 . No. 4 p.668 673. 